\title{
Current and Future Use of Radiological Images in the Management of Gynecological Malignancies - A Survey of Practice in the UK
}

\author{
JAMES DILLEY $^{1}$, PHILIP PRATT $^{1}$, MARIA KYRGIOU $^{2,3}$, KELSEY FLOTT $^{1}$, ARA DARZI $^{1}$ and ERIK MAYER ${ }^{1}$ \\ ${ }^{1}$ Department of Surgery and Cancer, Imperial College London, London, U.K.; \\ ${ }^{2}$ Institute of Reproductive and Developmental Biology, \\ Surgery and Cancer, Imperial College London, London, U.K.; \\ ${ }^{3}$ West London Gynaecological Cancer, Hammersmith Hospital, Imperial Healthcare NHS Trust, London, U.K.
}

\begin{abstract}
Background/Aim: Radiology provides increasingly accurate and complex information. Understanding the clinicians' interpretation of scans could improve surgical planning, decision-making; informed training and development of augmented imaging. This was a survey exploring the interpretation of imaging by clinicians and its use in operative preparation and prediction. Materials and Methods: The survey was open for two-months and circulated online to British Gynaecological Cancer society members. Results: Seventy-three (19\%) members completed the survey. Respondents had a confidence level of $51 \%$ in their ability to interpret computed tomography (CT) and/or magnetic resonance imaging (MRI) images independently. Preoperative imaging was commonly used to plan operations, predict complications and complete resection. Images were reviewed for primary (96.3\%)/interval (92.6\%) ovarian debulking, but less so for vulvectomy (45\%). Scan (79.6\%) and multidisciplinary team meeting (MDT) $(66.6 \%)$ reports were used more often than scan images (50\%) for operative planning. Amount and pattern of disease on scan were the most important factors predicting operating time. Conclusion: Imaging influences the surgeon's planning, however respondents lack confidence. Training of clinicians in radiological interpretation needs to improve. Augmented image interfaces could facilitate this.
\end{abstract}

It has now been a decade since all hospitals in the UK have allowed clinicians to directly access to patients' radiological

Correspondence to: Mr. Erik Mayer, Department of Surgery and Cancer, St Mary's Hospital Campus, 10th Floor, QEQM Building, Praed Street, Imperial College London, London W2 1NY, UK. Tel: +44 02033121310, Fax: +44 0203312 6950, e-mail: e.mayer@imperial.ac.uk

Key Words: Gynecology, radiology, images, management, training. imaging via the Picture Archiving and Communication System (PACS) (1). Traditionally an important tool in radiology departments, PACS is increasingly being used in nonradiological settings (2) allowing surgeons to access and view tomographic imaging independently for decision making and planning of procedures. There is little evidence, however, regarding how well used and beneficial this resource actually is or how it could be improved. A recent study exploring general surgeons interactions with images showed that there is a mixed ability with regards to interpretation (3), with the results prompting an increased focus on education and training (4).

In gynaecological oncology surgery, like other surgical specialties, has seen a shift towards a minimal access approach where possible $(5,6)$. This has increased the 'sensory distance' between the surgeon and the patient, reducing or removing haptic feedback to the surgeon (7). Developments in intraoperative image guidance platforms using patient imaging obtained pre-operatively, such as computed tomography (CT), magnetic resonance imaging (MRI) or ultrasound performed intraoperatively, have helped to compensate for this and have concurrently addressed surgical precision (8). Currently, the use of image guidance platforms in minimal access abdominal surgery is limited (7, 9). To develop these platforms the relationship between radiological images and gynaecological oncologists needs to be better understood. This evolution in surgical approach comes at a time when clinicians have an increasing complex array of imaging modalities available to them $(10,11)$. Image guidance platforms have the potential to bring together many of these and provide the surgeon with clear, comprehensive, clinically relevant information.

The objective of this survey was to better understand clinicians' behaviours in using imaging as a component of the pre-operative process, with findings used to understand training requirements and inform curriculum, evolve relationships with radiologists, and facilitate informed development of next- 
generation image guidance platforms. The survey aimed to explore four main areas: confidence when interpreting images, use of pre-operative imaging, pre-operative preparation and prediction of complications and operating time.

\section{Materials and Methods}

Survey design. The initial survey was developed by two gynaecologists and an expert in survey design. No appropriate preexisting surveys could be found relating to this area, thus relevant literature was used for additional guidance (12). The survey was designed and hosted using the Qualtrics survey software (www.qualtrics.com). The survey was tested by four gynaecologists who checked the survey for leading questions and indistinctness. The survey was further developed and refined in conjunction with the British Gynaecological Cancer Society (BGCS) survey design panel. A full validation of the survey was not performed as the purpose of this study was to design the survey as a tool for exploratory purposes, as opposed to the generation of a universal survey that could be used elsewhere. The final survey consisted of 12 questions, with options for providing additional information and one feedback/comments box (Figure 1). Participants were required to complete each question before they were able to move to the next. A proportion of the BGCS members did not perform gynaecological surgery and as such the survey was designed to filter out these members from answering questions related to surgery.

Survey distribution. The survey was distributed via an email to all BGCS members on the electronic mailing list (393 members) and could be accessed via an anonymous link. The survey was open for a twomonth period (October to December 2016) with a reminder email sent after one month. No incentive was offered for completion of the survey.

Data analysis. All data collected were analysed in Excel (Microsoft Corporation, Redmond, WA, USA). Only surveys that were $100 \%$ completed (excluding demographic information) were included in the analysis. Data were grouped depending on specialty, grade of surgeon and age. Out filtering of respondents' responses was dependent upon the question being asked and its relevance to their clinical speciality. For questions directly related to surgery only responses from surgeons were analysed.

\section{Results}

Demographics and background. The response rate was $19 \%$ $(73 / 393)$ of all BGCS members. The majority of the respondents $(44 \%)$ were consultant surgeons in gynaecological oncology, $12 \%$ were subspecialty trainees in gynaecological oncology and $10 \%$ were gynaecological oncology unit leads. Oncologists (clinical and medical) made up $17 \%$ of the respondents. Of the respondents, $44 \%$ had spent less than 10 years specializing in gynaecological oncology, with $35 \%$ spending between $11-20$ years, $17 \%$ spent $21-30$ years and $3 \%$ spent over 30 years (Table I).

Confidence when interpreting images. Overall respondents had a median confidence level of $51 \%(\mathrm{IQR}=30-71)$ in themselves, when asked about their ability to interpret correctly CT/MRI images on their own. The confidence level increased with grade. Consultants in gynaecological oncology had a confidence level of $63.5 \%$ (IQR=50-72). This group was sub-analyzed based on years in the specialty with an increase in confidence from $0-10$ years $(51 \%)$ to 11 20 years $(70 \%)$, but confidence was reduced in those practicing over 20 years $(55 \%)$. Subspecialty trainees had a lower confidence level of $50 \% \quad(\mathrm{IQR}=45-60)$ than consultants, as did gynaecology oncology unit leads $30 \%$ (IQR 15-45). Trainees in obstetrics and gynaecology had a confidence level of $22.5 \% \quad(\mathrm{IQR}=18.5-28.75)$, clinical oncologists $65.5 \% \quad(\mathrm{IQR}=57.5-76.25)$, and medical oncologists $32 \%(\mathrm{IQR}=29-69)$. Only radiologists had $100 \%$ confidence in interpreting images, while the pathologist had $50 \%$ confidence and the two clinical nurse specialists (CNS) had $2 \%$ (Figure 2).

Use of pre-operative imaging. Overall, 72.1\% (39/54) of respondents always, or very frequently, used imaging to help with planning operations. To predict complications $(53.6 \%$, 29/54) and ability to achieve complete resection/R0 (61.1\%, $33 / 54$ ) pre-operative imaging was used either always or very frequently. Pre-operative imaging was never used $(40.1 \%$, $22 / 54)$, very rarely $(9.3 \%, 5 / 54)$ or rarely used $(16.6 \%, 9 / 54)$ to brief the operating team. Conversely, pre-operative imaging was used always $(12.3 \%, 9 / 73)$, very frequently $(39.7 \%, 29 / 73)$ or occasionally $(26 \%, 19 / 73)$ in teaching and training. When examining how respondents currently use pre-operative imaging it can be appreciated that it is used only occasionally or less $(65 \%, 45 / 69)$ to explain disease status to patients (Table II).

Excluding time spent viewing scans in the multidisciplinary team meeting (MDT), the majority of respondents $(75.3 \%, 55 / 73)$ spent less than 10 min looking at each patient's radiological images (Table III). Stratified by type of operation, respondents did not look at images prior to the procedure for vulvectomy and inguinal lymphadenectomy $(55 \%, 30 / 54)$, total laparoscopic hysterectomy and bilateral salpingo-oophrectomy $(27.8 \%, 15 / 54)$ and inguinal (or other) sentinel node mapping $(18.5 \%, 10 / 54)$. Only $3.7 \%(2 / 54)$ of respondents did not look at imaging prior to primary ovarian debulking surgery, which increased to $7.4 \%$ (4/54) for interval debulking. Five point-six percent (3/54) did not view imaging before performing a pelvic exenteration. Respondents did not review images before radical hysterectomy $(9.3 \%, 5 / 54)$, radical trachelectomy $(11.1 \%, 6 / 54)$, pelvic $(14.8 \%, 8 / 54)$ and para-aortic $(11.1 \%, 6 / 54)$ lymphadenectomy. Usually, the preoperative images were viewed for the purpose of planning surgery at the time of the multidisciplinary team meeting or just before the operation. Having the imaging available to view during the procedure was the least common response (Table IV). 
Pre-operative preparation. The scan report $(79.6 \%, 43 / 54)$, followed by the MDT report $(66.6 \%, 36 / 54)$, was the most commonly used aid in the discussion and planning of the operation with members of the operating team. Half of the respondents $(50 \%, 7 / 54)$ used the scan itself to do this (Table III). Over half $(51.9 \%, 28 / 54)$ of surgeons used a form of mental preparation to warm up before the operation, with the second most common method being a vocal approach (16.7\%, 9/54). Only $3.7 \%(2 / 54)$ used a surgical simulator (Figure 3 ). Alternative methods provided were a briefing with their 'buddy' surgeon or viewing online videos of the operation. This contrasts against the $42.6 \%$ (23/54) of respondents who did not use any form of pre-operative rehearsal. The most common reason provided was that they did not know this was done $(47 \%)$, with other popular reasons being that they had performed the operation many times before (20\%), they did not have access to a simulator and they did not think it would be beneficial $(17 \%)$. Of the respondents who did not use any pre-operative rehearsal, $13 \%$ said they did not have access to a simulator and 3\% did not have enough time.

Complications and operating time in ovarian cancer. When asked which methods they used to predict possible intraoperative structural and anatomical complications, 92.6\% (50/54) used intraoperative findings, $90.7 \%$ (49/54) previous experience, $77.8 \%$ (42/54) clinical examination and $75.9 \%$ (41/54) used preoperative images. Only $9.2 \%(5 / 54)$ used a specific pre-operative scoring system. When respondents were asked to rank the most important factors in influencing their predicted total operating time for ovarian cancer surgery, $54.2 \%$ ranked the amount of disease seen on the scan as the most important. The second most important factor was the pattern of disease spread (45.8\%) and the third was patient factors, such as BMI, age and medical comorbidities (43.8\%) (Table V, Figure 4).

Feedback comments. Respondents were also encouraged to comment on their relationship with radiological imaging, detailing difficulties and offering suggestions as to how it could be improved to benefit themselves, the patient or the clinical workflow. Feedback revealed five main themes: 1) the need for improved training of gynaecologists in interpreting radiological images; 2) increased collaboration with radiologists being required to help understand images; 3 ) radiological images being too complicated for the patients to understand; 4) imaging does not provide accurate representation of findings at surgery and 5) the generation of 3-dimensional composite images to enable easier understanding.

\section{Discussion}

This survey revealed several important findings about the clinical use of radiological imaging in gynaecological oncology. Overall, respondents reported a confidence level of just over $50 \%$ in their own ability to interpret correctly the findings of radiological scans when viewing them independently. As would be expected, consultants in gynaecological oncology had higher confidence than subspecialty trainees or gynaecological oncology unit leads. Considering the majority of the respondents had either completed or were close to completing their training, this level of confidence is lower than that of the confidence levels of $86 \%$ of experienced general surgeons, as reported in a similar study by Butler et al. (4). This same study found that surgical residents were confident in reading radiological images only $33 \%$ of the time, which prompted the generation of a dedicated radiology curriculum (4). The Royal College of Obstetricians and Gynaecologists sub-specialisation programme (13) does provide training in radiology, however feedback from this survey's respondents suggests there is a need for increased and better training. Other feedback suggests that an even closer working relationship with radiologists needs to be established and a dedicated preoperative radiological image viewing session, in addition to multidisciplinary team meetings, could be beneficial. Reasons for why overall confidence levels are low need to be explored and addressed in the current training curriculum in gynaecological oncology.

A minority of respondents felt there was a need to view imaging for a vulvectomy and inguinal lymphadenectomy whereas almost all viewed imaging prior to performing primary ovarian debulking surgery. Both procedures are carried out via an open incision, providing the surgeon with full visual and haptic sensory input. However, the procedures are quite different in terms of complexity and duration of the surgical procedure, proximity of neighbouring organs and level of subsequent surgical planning required. These differences are important to acknowledge when directing future efforts in training and harnessing developments in imaging technology.

This survey illustrated that pre-operative imaging plays an important role in planning of operations, predicting complications and ability to resect all cancerous deposits. In keeping with the lack of strong evidence for the use of dedicated pre-operative complication scoring systems $(14,15)$, only $9.2 \%$ of respondents used these to predict complications.

Employing three-dimensional reconstructions of radiological images could further enhance the role of radiological images in the pre-operative setting. Studies have found that it can enhance communication between radiologists and the surgeon, leading to improved surgical accuracy (2). Wang et al. found that when providing the surgeon with interactive threedimensional anatomical plans prior to performing complex hepatectomy it led to improved prediction of resection boundaries and residual function, allowing a more radical procedure but increased safety (16). Wijsmuller et al. have shown that it is possible to generate a three-dimensional map of pelvic nerves (17). Providing the surgeon with this could 
Q1 Age

O $<25$ years

O 25-34 years

O $35-44$ years

O $45-54$ years

O 55-64 years

O $>65$ years

Q2 Please select your current clinical position

O Consultant gynaecology oncologist

O Sub specialty trainee in gynaecology oncology

- Consultant with special interest in gynaecology oncology

O Consultant obstetrician gynaecologist

- Trainee in obstetrics and gynaecology

Clinical oncologist

- Medical oncologist

O Clinical nurse specialist

- Radiologist

O Pathologist

O Other

Q3 Number of years working within the field of gynaecological cancer

O $0-10$ years

O 11-20 years

- 21-30 years

- $31-40$ years

O $>40$ years

I I do not work in this field

Q4 How confident do you feel about your ability to interpreting CT/MRI images when viewing them on your own? Please indicate on scale below. $\underline{0}$

$100 \%$
Q5 How often do you use patient imaging to do the following?

\begin{tabular}{|c|c|c|c|c|c|c|}
\hline & Always & $\begin{array}{l}\text { Very } \\
\text { Frequently }\end{array}$ & $\begin{array}{l}\text { Occasion- } \\
\text { ally }\end{array}$ & Rarely & $\begin{array}{l}\text { Very } \\
\text { Rarely }\end{array}$ & Never \\
\hline $\begin{array}{l}\text { Explain disease/ } \\
\text { procedures to } \\
\text { patients }\end{array}$ & 0 & 0 & 0 & 0 & 0 & 0 \\
\hline Plan operation & 0 & 0 & 0 & 0 & 0 & O \\
\hline $\begin{array}{l}\text { Predict } \\
\text { complications }\end{array}$ & 0 & O & 0 & 0 & 0 & 0 \\
\hline $\begin{array}{l}\text { Predict ability to } \\
\text { achieve R0 }\end{array}$ & 0 & 0 & 0 & 0 & 0 & 0 \\
\hline $\begin{array}{l}\text { Brief theatre } \\
\text { team }\end{array}$ & 0 & o & 0 & 0 & 0 & 0 \\
\hline $\begin{array}{l}\text { Teach } \\
\text { trainees/students }\end{array}$ & 0 & 0 & 0 & 0 & 0 & 0 \\
\hline
\end{tabular}

Q6 Excluding time spent in the MDT, how long would you say you spend looking at each patient's radiological images

O $0-10 \mathrm{~min}$

O $10-20 \mathrm{~min}$

O $20-30 \mathrm{~min}$

O $>30 \mathrm{~min}$

Thank you

The rest of the survey relates to performing gynaecological surgery.

Please use free text box below to add any other thoughts as to how radiological imaging could be beneficial in the preoperative setting.

Q7 For which operation do you NOT look at scan prior to procedure

․ Vulvectomy + inguinal lymphadenectomy (LND)

- Inguinal (or other) Sentinel node mapping

a $\mathrm{TLH}+\mathrm{BSO}$

Pelvic LN sampling/dissection

Para-aortic LN sampling/dissection

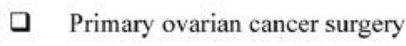

- Interval debulking surgery

Pelvic Exenteration (Anterior/Posterior/Total) 
Radical hysterectomy

․ Radical Trachelectomy

Q8 When do you look at the scans for the above operations

MDT

Days prior to surgery

Just before operation

Have view available during operation

Q9 Thinking about ALL types of operations, what do you use when discussing and planning operations with the operating team? Select all that apply

․ MDT report

- Scan report

․ Scan images

O Others

ㅁ. None of the above

Q10 Do you use any of the following methods to perform pre-operative rehearsal or surgical warm up prior to the operation? Select all that apply

aental

- Simulator based

․ Vocal

Other

ㅁ Do not use

Q10a If you do NOT use any pre-operative rehearsal or surgical warm, why not?

I I do not have enough time

I have and I have not found it helpful

I do not think it would be beneficial

I I do not have access to a simulator

I I did not know that this was done

I I have performed the operation many times already

ather

Figure 1. Survey design.
Q11 Which of the following methods do you use to predict possible complications (intraoperative structural/anatomical rather than metabolic). Select all that apply

a Experience

- Clinical examination

anowledge gained from pre-operative images

- Intra operative findings

- Specific complication scoring system

Q12 With regards to ovarian cancer debulking surgery, please rank the importance that the following factors have in influencing your predictions of total operating time $(1=$ most, $7=$ least $)$ Move the text boxes to rank.

Amount of disease seen on scan

Map of the disease spread

Patient factors (e.g. age, chronic renal disease)

Histology subtype

Efficiency of theatre team

Experience of surgical assistant

Surgeon fatigue

Thank you. Please use free text box below to add any other thoughts as to how radiological imaging could be of further utilised to be of increased benefit to themselves, the patient or the clinical workflow in the preoperative/operative setting. 


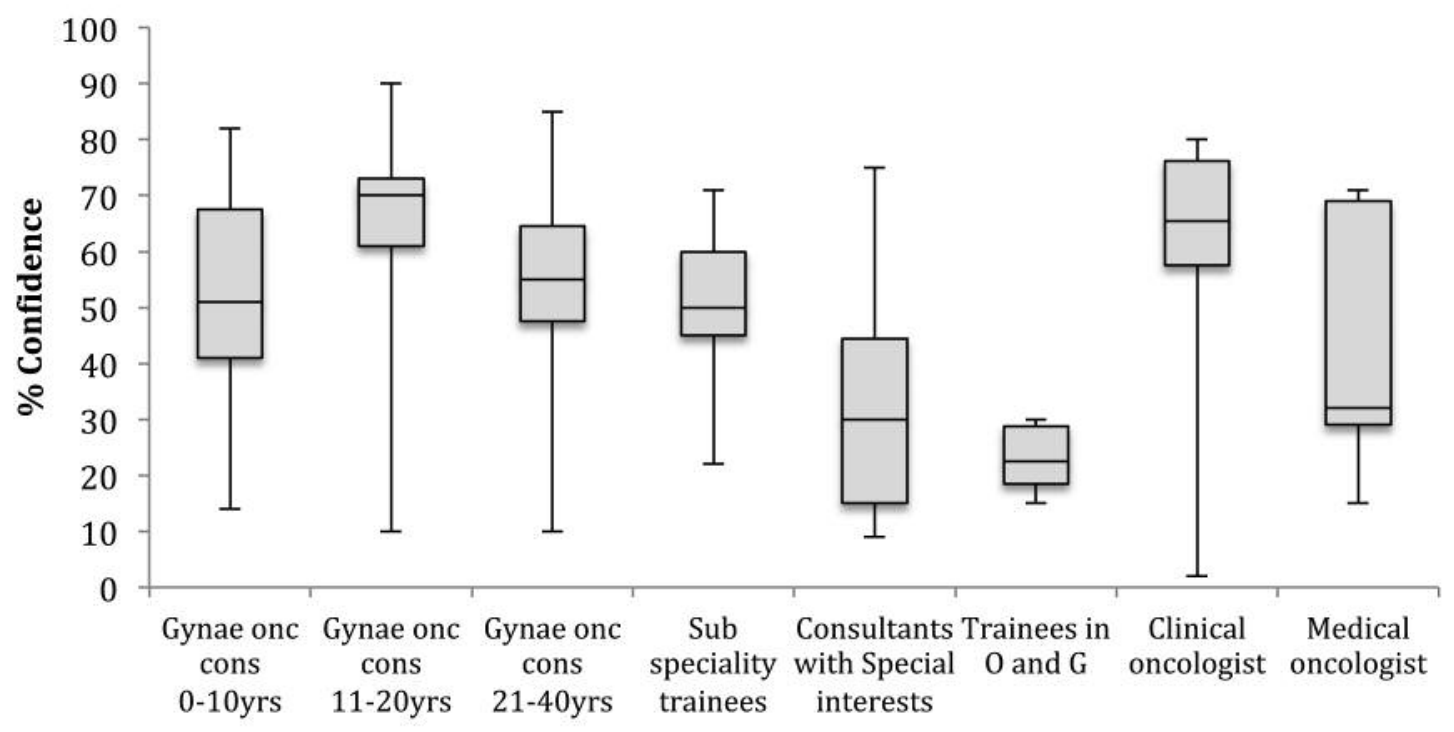

\section{Type of clinician*}

Figure 2. Confidence in interpreting CT/MRI images when different doctors viewed them on their own. Median and IQR shown. *Radiologist ( $n=1)$, pathologist $(n=1)$ and $C N S(n=2)$ are not represented.

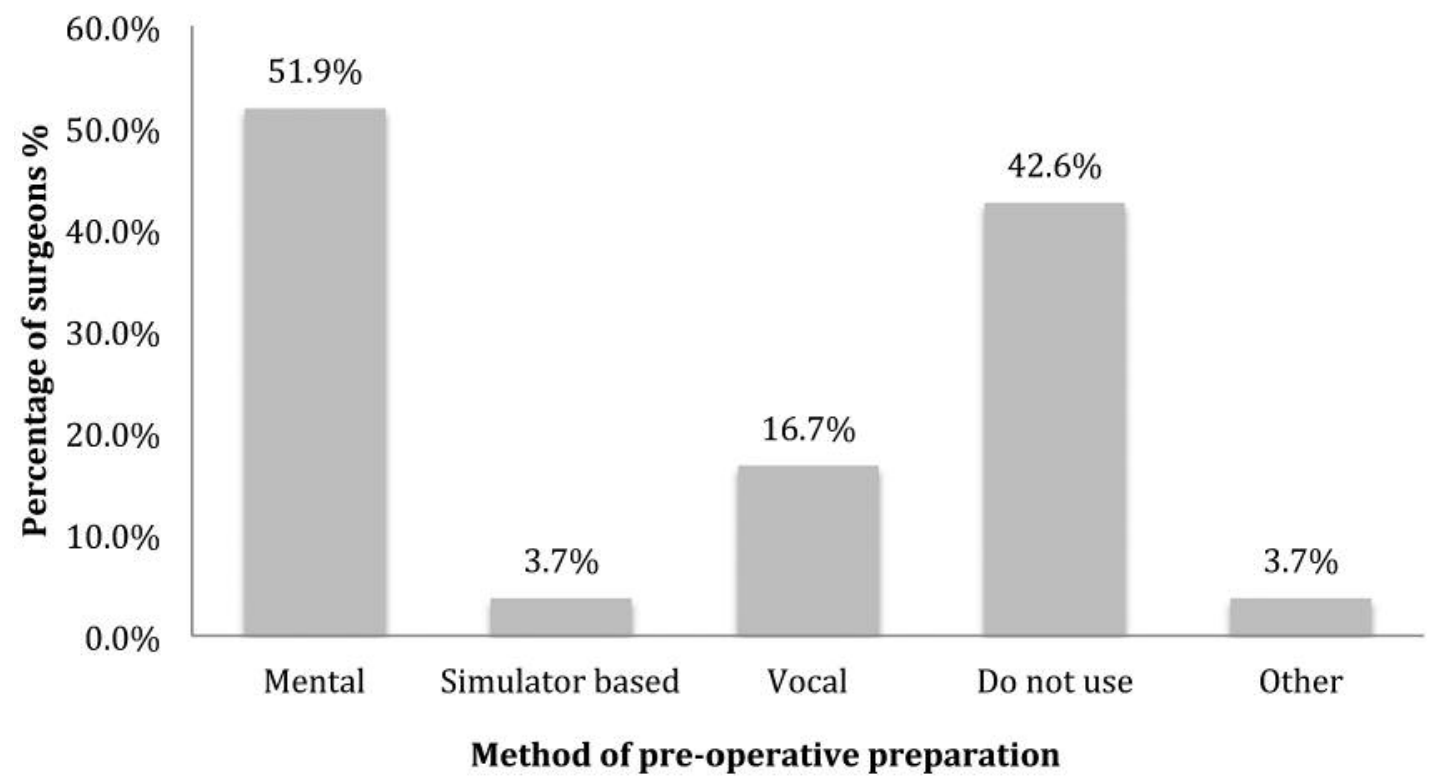

Figure 3. Methods of pre-operative preparations used by clinicians.

help to prevent and decrease intraoperative nerve injury. Studies have also shown that by enhancing the anatomical map available to the surgeon it can improve orientation and confidence (18). Furthermore, in this study respondents reported that both the amount of disease and pattern of disease, which can be determined by looking at the radiological images, are the most important factors influencing operating time.

Of the respondents who did perform pre-operative warm up, the majority (51.9\%) used a mental method. This is encouraging as mental practice has been shown to improve surgeon 
Table I. Demographic information of respondents.

\begin{tabular}{|c|c|c|c|c|c|}
\hline Position & $\begin{array}{l}\text { Number of } \\
\text { respondents }\end{array}$ & $\begin{array}{l}\text { Age group } \\
\text { (years) }\end{array}$ & $\begin{array}{l}\text { Number of } \\
\text { respondents }\end{array}$ & $\begin{array}{c}\text { Time working in gynaecology } \\
\text { oncology (years) }\end{array}$ & $\begin{array}{l}\text { Number of } \\
\text { respondents }\end{array}$ \\
\hline Gynaecology oncology consultants & 32 & $25-34$ & 8 & $0-10$ & 31 \\
\hline Consultants with special interest & 7 & $35-44$ & 26 & $11-20$ & 26 \\
\hline Subspecialty trainees & 9 & $45-54$ & 20 & $21-30$ & 12 \\
\hline $\mathrm{O}$ and $\mathrm{G}$ trainees & 6 & $55-64$ & 16 & $31-40$ & 2 \\
\hline Medical Oncologist & 5 & $>65$ & 1 & N/A & 1 \\
\hline Clinical Oncologist & 8 & N/A & 2 & & \\
\hline Radiologist & 1 & & & & \\
\hline Pathologist & 1 & & & & \\
\hline CNS & 2 & & & & \\
\hline Other & 2 & & & & \\
\hline
\end{tabular}

Table II. Current use of patient imaging by respondents.

\begin{tabular}{lcccccc}
\hline & Always n (\%) & Very Frequently n (\%) & Occasionally n (\%) & Rarely n (\%) & Very rarely n (\%) & Never n (\%) \\
\hline Explain disease to patient (n=69) & $9(13.0)$ & $15(21.7)$ & $24(34.7)$ & $5(7.2)$ & $9(13.0)$ & $7(10.1)$ \\
Plan operation (n=54) & $21(38.8)$ & $18(33.3)$ & $2(3.7)$ & $2(3.7)$ & $2(3.7)$ & $9(16.6)$ \\
Predict complication $(\mathrm{n}=54)$ & $9(16.6)$ & $20(37.0)$ & $10(18.5)$ & $6(11.1)$ & $3(5.5)$ & $6(11.1)$ \\
Predict R0 (n=54) & $13(24.1)$ & $20(37.0)$ & $6(11.1)$ & $2(3.7)$ & $6(11.1)$ & $7(12.9)$ \\
Brief theatre team (n=54) & $4(7.4)$ & $7(12.9)$ & $7(12.9)$ & $9(16.6)$ & $5(9.3)$ & $22(40.1)$ \\
Teach/Train $(\mathrm{n}=73)$ & $9(12.3)$ & $29(39.7)$ & $19(26.0)$ & $7(9.6)$ & $5(6.8)$ & $4(5.5)$ \\
\hline
\end{tabular}

performance $(19,20)$. However, it is concerning that even though there are clear benefits to pre-operative preparation, almost half of the respondents who did not use any form of preoperative warm up were not even aware of it being available.

Imaging is only occasionally used to help explain the disease status and surgical procedure to the patient. Feedback from the respondents suggested that this is due to scans being too complicated to show to patients, and thus are not able to appreciate what is being shown to them. A study by Bollschweiler et al. showed that imaging could play an important role in persuading the patient to sign the informed consent, and can be particularly beneficial to those with a lower level of education (21). Additionally, when used in sinus surgery, by providing a more intuitive three-dimensional segmented representation of the anatomy, patients had an improved understanding of the anatomy and possible postsurgical complications pre-operatively and also had higher satisfaction with the procedure (22). Importantly, this did not lead to an increase in patient anxiety. Despite the scan report being the most popular adjunct to help the operating team in discussing and planning the procedure, the pre-operative imaging itself was very rarely or never used by approximately half of the respondents. There are many possible reasons for this mismatch, including lack of facilities in theatre, scans
Table III. Top-Time spent outside of MDT looking at each patient's radiological images. Bottom-Modalities used by respondents when discussing and planning operations with the operating team.

\begin{tabular}{lcc}
\hline Time in min & $\%$ & Number of respondents $(\mathrm{n}=73)$ \\
\hline $0-10$ & 75.3 & 55 \\
$10-20$ & 13.7 & 10 \\
$20-30$ & 4.1 & 3 \\
$>30$ & 5.5 & 4 \\
\hline & & \\
\hline Modality used & $\%$ & Number of respondents $(\mathrm{n}=54)$ \\
\hline MDT report & 66.6 & 36 \\
Scan report & 79.6 & 43 \\
Scan images & 50.0 & 27 \\
Others & 5.6 & 3 \\
\hline
\end{tabular}

being difficult to understand, and a lack of radiological training for some of the team members.

Findings from this survey suggest that clinicians are not confident in interpreting radiological images by themselves. With medical imaging increasing in complexity, this problem 


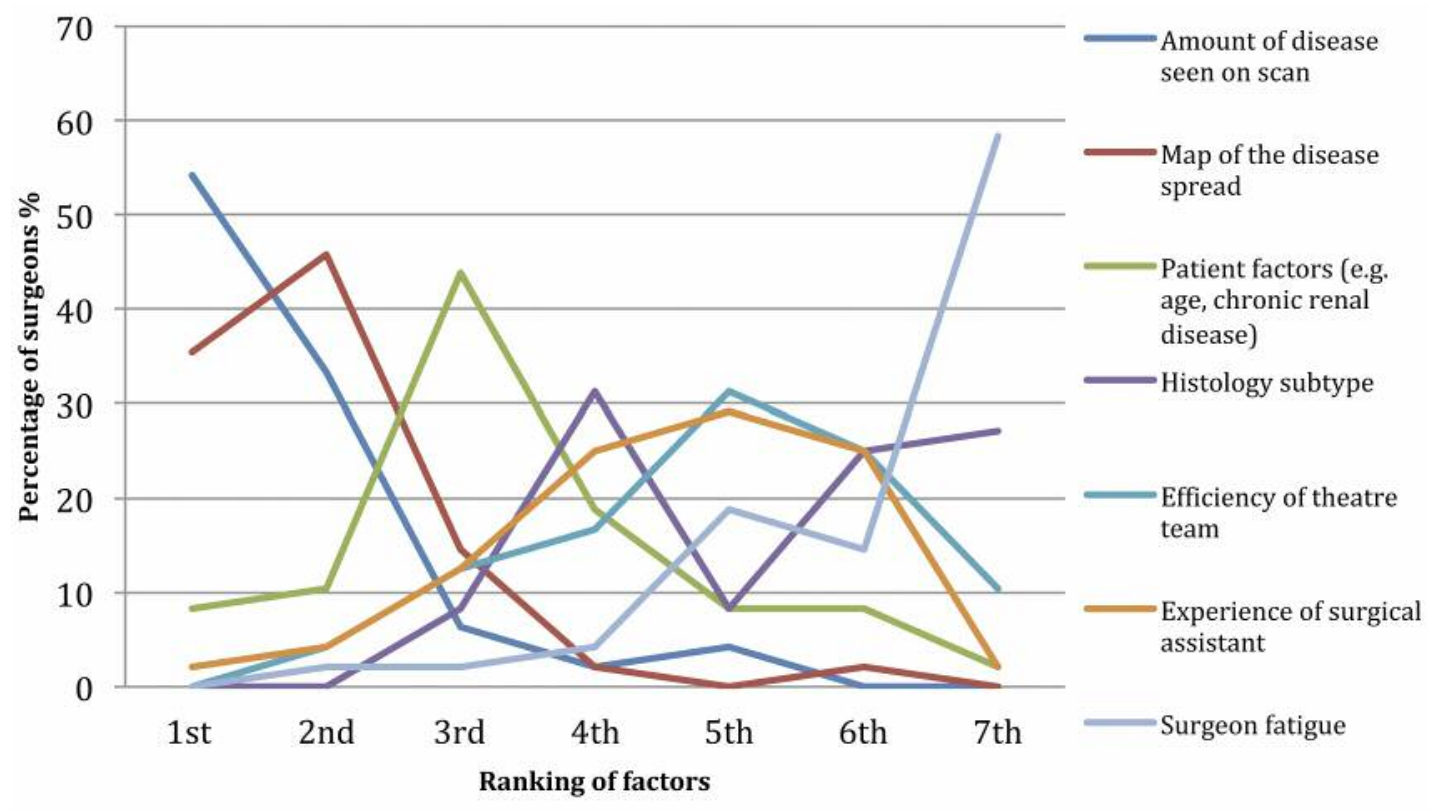

Figure 4. Ranking in order of importance on factors that influence total operating time prediction in ovarian cancer debulking surgery.

Table IV. Review of images by surgeon prior to the procedure and timing of viewing.

\begin{tabular}{|c|c|c|c|c|c|}
\hline \multirow[t]{2}{*}{ Type of operation $(n=54)$} & \multirow{2}{*}{$\begin{array}{l}\text { Operations where } \\
\text { surgeon does NOT } \\
\text { look at scan n }(\%)\end{array}$} & \multicolumn{4}{|c|}{ Timing of viewing scan when viewed prior to operation } \\
\hline & & $\begin{array}{c}\text { MDT } \\
n\end{array}$ & $\begin{array}{c}\text { Days prior } \\
\text { to surgery } \\
n\end{array}$ & $\begin{array}{c}\text { Just before } \\
\text { operation } \\
n\end{array}$ & $\begin{array}{c}\text { Have view available } \\
\text { during operation } \\
n\end{array}$ \\
\hline Vulvectomy + inguinal lymphadenectomy (LND) & $30(55 \%)$ & 23 & 3 & 6 & 0 \\
\hline Inguinal (or other) Sentinel node mapping & $10(18.5)$ & 32 & 3 & 19 & 7 \\
\hline $\mathrm{TLH}+\mathrm{BSO}$ & $15(27.8)$ & 27 & 14 & 15 & 3 \\
\hline Pelvic LN sampling/dissection & $8(14.8)$ & 41 & 9 & 21 & 2 \\
\hline Para-aortic LN sampling/dissection & $6(11.1)$ & 43 & 13 & 23 & 7 \\
\hline Primary ovarian cancer surgery & $2(3.7)$ & 50 & 14 & 30 & 8 \\
\hline Interval debulking surgery & $4(7.4)$ & 48 & 14 & 30 & 7 \\
\hline Pelvic Exenteration (Anterior/Posterior/Total) & $3(5.6)$ & 47 & 21 & 31 & 4 \\
\hline Radical hysterectomy & $5(9.3)$ & 45 & 10 & 23 & 3 \\
\hline Radical Trachelectomy & $6(11.1)$ & 36 & 8 & 17 & 3 \\
\hline
\end{tabular}

TLH: Total laparoscopic hysterectomy; BSO: bilateral salpingo-oophrectomy; LN: lymph node.

threatens to become larger. A closer collaboration of clinicians with radiologists should be made. However, time pressures on both the radiologists and clinicians will prevent this from solving the problem completely. A potential solution is to provide three-dimensional augmented displays with a composite of information to create a bridge between increasingly complex medical images and user friendly, accessible images for the clinician on which to base their patient management. Future studies should explore the impact this technology may bring both to the surgeon and to the interactions with the operating team and patients.

This survey offers an accurate and up-to-date summary of the use of radiological imaging in gynaecological cancer in the UK. The response rate of $19 \%$ of BGCS members is an obvious limitation of the survey. However, it is in keeping with previous survey responses from the society and not an uncommon issue in survey-based studies. The survey was not designed to allow respondents to provide reasons for why they 
Table V. Rates in order of importance on factors that influence total operating time prediction in ovarian cancer debulking surgery.

\begin{tabular}{|c|c|c|c|c|c|c|c|}
\hline Factor & $\begin{array}{c}1 \text { st } \\
\mathrm{n}(\%)\end{array}$ & $\begin{array}{c}\text { 2nd } \\
\mathrm{n}(\%)\end{array}$ & $\begin{array}{c}3 \mathrm{rd} \\
\mathrm{n}(\%)\end{array}$ & $\begin{array}{c}\text { 4th } \\
\mathrm{n}(\%)\end{array}$ & $\begin{array}{c}5 \text { th } \\
\mathrm{n}(\%)\end{array}$ & $\begin{array}{c}\text { 6th } \\
\mathrm{n}(\%)\end{array}$ & $\begin{array}{c}7 \text { th } \\
\mathrm{n}(\%)\end{array}$ \\
\hline Amount of disease seen on scan & $26(54.2)$ & $16(33.3)$ & $3(6.3)$ & $1(2.1)$ & $2(4.2)$ & $0(0.0)$ & $0(0.0)$ \\
\hline Map of the disease spread & $17(35.4)$ & $22(45.8)$ & $7(14.6)$ & $1(2.1)$ & $0(0.0)$ & $1(2.1)$ & $0(0.0)$ \\
\hline Patient factors (e.g. age, chronic renal disease) & $4(8.3)$ & $5(10.4)$ & $21(43.8)$ & $9(18.8)$ & $4(8.3)$ & $4(8.3)$ & $1(2.1)$ \\
\hline Histology subtype & $0(0.0)$ & $0(0.0)$ & $4(8.3)$ & $15(31.3)$ & $4(8.3)$ & $12(25.0)$ & $13(27.1)$ \\
\hline Efficiency of theatre team & $0(0.0)$ & $2(4.2)$ & $6(12.5)$ & $8(16.7)$ & $15(31.3)$ & $12(25.0)$ & $5(10.4)$ \\
\hline Experience of surgical assistant & $1(2.1)$ & $2(4.2)$ & $6(12.5)$ & $12(25.0)$ & $14(29.2)$ & $12(25.0)$ & $1(2.1)$ \\
\hline Surgeon fatigue & $0(0.0)$ & $1(2.1)$ & $1(2.1)$ & $2(4.2)$ & $9(18.8)$ & $7(14.6)$ & $28(58.3)$ \\
\hline
\end{tabular}

had low levels of confidence in interpreting scans, which should be addressed in future studies. Increased communication with radiologists was one of the five feedback themes. This survey did not have the capacity to develop on this aspect, but future work should explore access and time spent with radiologist and the influence this has on the surgeon's approach. Finally, the survey did not distinguish between MRI and CT images. MRI images can be considered more difficult to interpret. Understanding this may enable direction of training and where three-dimensional image augmentation could be of greatest benefit.

\section{Conclusion}

Pre-operative imaging plays a vital role in influencing the surgeon in their operative planning and prediction of complications. Surgeons report that they lack confidence in their ability to interpret medical images. This naturally creates a barrier to integrating fully this important source of information during pre-operative decision-making. Improving training and working more closely with radiologists is a potential solution. However, with increased demands on already pressured specialist training as well as high workload being experienced by radiologists, this may not be feasible. User interfaces developed as part of intraoperative image guidance platforms could play a further role in the pre-operative setting to overcome this issue.

\section{Conflicts of Interest}

There are no conflicts of interest regarding this study.

\section{Acknowledgements}

This study is independent research funded by the National Institute for Health Research (NIHR) Imperial Biomedical Research Centre (BRC), the Genesis Research Trust (Garfield Weston Foundation, P63522 to MK); and Ovarian Cancer Action (MK). The views expressed in this publication are those of the authors and not necessarily those of the NHS, the National Institute for Health Research nor the Department of Health. None of the funders had any influence on the study design; in the collection, analysis, and interpretation of data; in the writing of the report; and in the decision to submit the article for publication.

\section{References}

1 Sutton LN: PACS and diagnostic imaging service delivery - A UK perspective. Eur J Radiol 78: 243-249, 2011.

2 Faggioni L, Neri E, Castellana C, Caramella D and Bartolozzi $\mathrm{C}$ : The future of PACS in healthcare enterprises. Eur J Radiol 78: 253-258, 2011.

3 Eid JJ, Macedo FIB, Negussie E and Mittal VK: Assessing surgical residents' imaging interpretation skills. Am J Surg 213: 498-501, 2017.

4 Butler KL, Chang Y, Demoya M, Feinstein A, Ferrada P, Maduekwe U, Maung AA, Melo N, Odom S, Olasky J, Reinhorn M, Smink DB, Stassen N, Wilson CT, Fagenholz P, Kaafarani H, King D, Yeh DD, Velmahos G and Stefanidis D: Needs assessment for a focused radiology curriculum in surgical residency: A multicenter study. Am J Surg 211: 279287, 2016.

5 Cho JE, Liu C, Gossner G and NEZHAT FR: Laparoscopy and Gynecologic Oncology. Clin Obstet Gynecol 52: 313-326, 2009.

6 Rimbach S, Neis K, Solomayer E, Ulrich U and Wallwiener D: Current and future status of laparoscopy in gynecologic oncology. Geburtshilfe Frauenheilkd 74: 852-859, 2014.

7 Bernhardt S, Nicolau SA, Soler L and Doignon C: The status of augmented reality in laparoscopic surgery as of 2016. Med Image Anal 37: 66-90, 2017.

8 Bégin A, Martel G, Lapointe R, Belblidia A, Lepanto L, Soler L, Mutter D, Marescaux J and Vandenbroucke-Menu F: Accuracy of preoperative automatic measurement of the liver volume by CTscan combined to a 3D virtual surgical planning software (3DVSP). Surg Endosc Other Interv Tech 28: 3408-3412, 2014.

9 Wijsmuller AR, Romagnolo LGC, Agnus V, Giraudeau C, Melani AGF, Dallemagne B and Marescaux J: Advances in stereotactic navigation for pelvic surgery. Surg Endosc Other Interv Tech $0: 1-8,2017$.

10 Lakhani A, Khan SR, Bharwani N, Stewart V, Rockall AG, Khan $\mathrm{S}$ and Barwick TD: FDG PET/CT Pitfalls in gynecologic and genitourinary oncologic imaging. RadioGraphics 37: 577-594, 2017. 
11 Prabhakar HB, Kraeft JJ, Schorge JO, Scott JA and Lee SI: FDG PET-CT of gynecologic cancers: pearls and pitfalls. Abdom Imaging 40: 2472-2485, 2015.

12 Bucholz R: Introduction to journal of image guided surgery [editorial]. J Image Guid Surg 1: 1-3, 1995.

13 RCOG: https://www.rcog.org.uk/en/careers-training/specialtytraining-curriculum/subspecialty-training/gynaecologicaloncology-subspecialty-training/.

14 Clark RM, Lee MS, Alejandro Rauh-Hain J, Hall T, Boruta DM, Del Carmen MG, Goodman A, Schorge JO and Growdon WB: Surgical Apgar Score and prediction of morbidity in women undergoing hysterectomy for malignancy. Gynecol Oncol 136: 516-520, 2015.

15 Das N, Talaat AS, Naik R, Lopes AD, Godfrey KA, Hatem MH and Edmondson RJ: Risk adjusted surgical audit in gynaecological oncology: P-POSSUM does not predict outcome. Eur J Surg Oncol 32: 1135-1138, 2006.

16 Wang X-D, Wang H-G, Shi J, Duan W-D, Luo Y, Ji W-B, Zhang $\mathrm{N}$ and Dong J-H: Traditional surgical planning of liver surgery is modified by $3 \mathrm{D}$ interactive quantitative surgical planning approach: a single-center experience with 305 patients. Hepatobiliary Pancreat Dis Int 16: 271-278, 2017.

17 Wijsmuller AR, Giraudeau C, Leroy J, Kleinrensink GJ, Rociu E, Romagnolo LG, Melani AGF, Agnus V, Diana M, Soler L, Dallemagne B, Marescaux J and Mutter D: A step towards stereotactic navigation during pelvic surgery: 3D nerve topography. Surg Endosc Other Interv Tech 0: 1-10, 2018.
18 Lamata P, Lamata F, Sojar V, Makowski P, Massoptier L, Casciaro S, Ali W, Stüdeli T, Declerck J, Elle OJ and Edwin B: Use of the resection map system as guidance during hepatectomy. Surg Endosc Other Interv Tech 24: 2327-2337, 2010.

19 Arora S, Aggarwal R, Sirimanna P, Moran A, Grantcharov T, Kneebone R, Sevdalis N and Darzi A: Mental practice enhances surgical technical skills: a randomized controlled study. Ann Surg 253: 265-270, 2011.

20 Schreinemacher MHF, Ten Broek RP, Bakkum EA, Van Goor H and Bouvy ND: Adhesion awareness: A national survey of surgeons. World J Surg 34: 2805-2812, 2010.

21 Bollschweiler E, Apitsch J, Obliers R, Koerfer A, Mönig SP, Metzger R and Hölscher AH: Improving Informed Consent of Surgical Patients Using a Multimedia-Based Program? Ann Surg 248: 205-211, 2008.

22 Victores A, Huynh N, Yao W, Butler E and Takashima M: ThreeDimensional Imaging for Improving Patient Education as it Relates to Sinus Disease. In: 2012 AAO-HNSF Annual Meeting \& OTO EXPO, 2012.
Received August 25, 2018

Revised September 23, 2018

Accepted September 24, 2018 